\title{
MOBILIZAÇÃO POLÍTICA NEGRA NO BRASIL, $1975-1990^{1}$
}

\author{
Black political mobilization in Brazil, 1975-1990
}

\author{
George Reid Andrews"
}

\begin{abstract}
RESUMO
A maioria dos estudos acadêmicos sobre a redemocratização presta atenção considerável aos movimentos organizados de oposição que emergiram nestes anos; nenhum deles, no entanto, faz qualquer menção ao movimento negro. Este artigo examina o movimento político negro que emergiu durante a abertura, um processo de onze anos (1974-1985) em que o Brasil fez a transição gradual da ditadura militar para uma democracia civil.
\end{abstract}

Palavras-chave: ditadura; redemocratização; movimento negro.

\begin{abstract}
The major scholarly treatments of redemocratization pay considerable attention to the organized opposition movements which emerged during those years; none of them, however, make any mention at all of the black movement. This article examines the Afro-Brazilian political movement which emerged during the abertura, the eleven-year (1974-1985) process by which Brazil made a gradual, phased transition from military dictatorship to civilian democracy.
\end{abstract}

Keywords: dictatorship; redemocratization; black movement.

1 Tradução de "Black Political Mobilization in Brazil, 1975-1990," em George Reid Andrews e Herrick Chapman, eds., The Social Construction of Democracy, 1870-1990 (Nova York, 1995), () New York University 1995. Tradução de Mariângela Nogueira. Nota dos organizadores do dossiê: O artigo foi publicado originalmente nos USA em meados da década de 1990, mas, devido à sua relevância para a temática, decidimos convidar o autor para traduzi-lo e publicá-lo no Brasil, em vista de que um maior número de pesquisadores e estudantes tenha acesso a ele.

* Ph.D. Universidade de Wisconsin. Professor da Universidade de Pittsburgh (EUA) 
Este artigo examina o movimento político negro que emergiu durante a abertura, um processo de onze anos (1974-1985) em que o Brasil fez a transição gradual da ditadura militar para uma democracia civil. A maioria dos estudos acadêmicos sobre a abertura presta atenção considerável aos movimentos organizados de oposição que emergiram nestes anos; nenhum deles, no entanto, faz qualquer menção ao movimento negro. ${ }^{2}$

Esta negligência deve-se, sem dúvida, à incapacidade do movimento para influenciar a política eleitoral ou a formulação de políticas nos últimos anos da ditadura (1964-1985), ou nos primeiros anos da Terceira República (1985 até o presente [1995]). Em parte, por razões comuns a qualquer movimento popular no Brasil, mas também por razões especificas da população afro-brasileira, o movimento negro mostrou-se inábil em mobilizar seu almejado eleitorado: os $45 \%$ da população brasileira que são afrodescendentes puros ou miscigenados. ${ }^{3}$ Paradoxalmente, contudo, sua influência e seus esforços de conscientização tiveram considerável impacto nas elites políticas, culturais e intelectuais. Em fins dos anos oitenta, apesar da falta de uma base popular forte, os ativistas negros conseguiram provocar um vigoroso debate nacional sobre a desigualdade racial e o papel da população negra na vida brasileira. $\mathrm{O}$ debate centrou-se no conceito de democracia racial, uma ideologia semioficial originalmente destinada a descrever e explicar a sociedade

2 Ver, por exemplo, Maria Helena Moreira Alves, State and Opposition in Military Brazil (Austin, 1985); Thomas E. Skidmore, The Politics of Military Rule in Brazil, 1964-1985 (Nova York: 1988); Alfred Stepan, ed., Democratizing Brazil: Problems of Transition and Consolidation (Nova York, 1988). Sobre o Movimento Negro durante estes anos, ver Michael Mitchell, "Blacks and the Abertura Democrática", em Pierre-Mitchell Fontaine, ed., Race, Class and Power in Brazil (Los Angeles, 1985); George Reid Andrews, Blacks and Whites in São Paulo, Brazil, 1888-1988 (Madison, 1991), 191-207, 216-33; Michael George Hanchard, "Orpheus and Power: The Movimento Negro of Rio de Janeiro and São Paulo, 1945-1988” (Tese de Doutorado, Universidade de Princeton, 1991).

3 A população total do Brasil em 1980 era de 119 milhões, dos quais 64,5 milhões eram brancos, 64,2 milhões, pardos, 7,1 milhões de pretos, 0,7 milhões de asiáticos e 0,5 milhões de raça não declarada. Instituto Brasileiro de Geografia e Estatística (doravante IBGE), Recenseamento Geral do Brasil - 1980. Censo Demográfico (Rio de Janeiro, 1983), Tabela 1.4, 10-11. Nos últimos anos, as pesquisas do IBGE combinam pardos e pretos em uma única categoria, negros; ver, por exemplo, Lúcia Helena Garcia de Oliveira et al., O lugar do negro na força de trabalho (Rio de Janeiro: 1985). No restante deste capítulo, usarei "negro" neste sentido mais amplo, para indicar pessoas de ascendência africana pura e misturada. 
e a cultura brasileiras, mas que, como seu título sugere, provou ser aplicável também às questões de democracia política.

\section{Democracia racial e democracia política}

A ideologia de democracia racial reivindica que o Brasil é inteiramente livre de impedimentos legais e institucionais à igualdade racial e, em grande medida (particularmente em comparação com países como os Estados Unidos), livre também de preconceito e discriminação racial informal. A Nação alega oferecer a seus cidadãos, negros, mestiços ou brancos, praticamente a mesma igualdade de oportunidades em todas as áreas da vida pública: educação, política, emprego, habitação. De acordo com os defensores da ideologia, os afro-brasileiros desfrutam de oportunidade de prosperar e de liberdade para competir com seus concidadãos em concorrências públicas e privadas num nível desconhecido em qualquer outra sociedade multirracial do mundo. ${ }^{4}$

As raízes da democracia racial estendem-se bem para trás, até o século dezenove, nas observações de viajantes estrangeiros e de brasileiros sobre a suavidade da escravidão brasileira e o grande alcance das oportunidades de prosperidade e mobilidade social para negros e mestiços livres. A ideologia recebeu sua mais completa e mais coerente formulação, no entanto, na década de 1930, como parte de uma ampla base nacional de protesto contra o autoritarismo oligárquico e a política social repressiva da Primeira República (1891-1930).

Apesar de definir-se como uma democracia eletiva, a República foi um regime oligárquico completamente dominado pela

4 Sobre democracia racial, ver Florestan Fernandes, A integração do negro na sociedade de classes, $3^{a}$ edição (São Paulo, 1978), I, 249-69; Emília Viotti da Costa, The Brazilian Empire: Myths and Histories (Chicago, 1985), pp. 234-46; Thales de Azevedo, Democracia racial (Petrópolis, 1975); Carlos Hasenbalg, "Race Relations in Modem Brazil" (Albuquerque, 1985); Hanchard, "Orpheus and Power", 48-95 e passim. 
elite latifundiária. Os sufrágios foram reduzidos ao mínimo (somente em duas eleições presidenciais, entre 1890 e 1930, o número de eleitores foi maior que $3 \%$ da população brasileira), a disputa partidária praticamente não existia e os nascentes sindicatos e outros movimentos populares sofriam severa repressão. ${ }^{5}$

Reforçando a tendência política de exclusão, havia uma série de políticas sociais baseadas no racismo científico e no darwinismo social dominantes no ocidente naquele tempo. No esforço de "branquear" a população nacional e reduzir a dependência dos patrões em relação ao trabalho de seus ex-escravos (a Abolição foi proclamada em 1888), os governos estaduais e o governo federal republicano promoveram uma massiva imigração europeia. ${ }^{6}$

De modo inevitável, esta campanha para europeizar o Brasil impactou severamente a população afro-brasileira, sobretudo em São Paulo e nos estados do Sul, onde a imigração foi mais intensa. Os trabalhadores europeus contaram com a preferência oficial e não oficial em fazendas e fábricas durante este período, enquanto os trabalhadores negros foram relegados às margens dos mercados de trabalho nas cidades e nos campos. ${ }^{7}$ Contudo, a chegada de europeus mostrou-se problemática também para os trabalhadores brancos, a classe média e até a elite agrária que tinha inicialmente apoiado a imigração. Os imigrantes, e mais tarde seus filhos, tornaram-se concorrentes diretos dos brasileiros trabalhadores, negociantes e pequenos comerciantes. E para horror da elite, embora os imigrantes indubitavelmente contribuíssem para o branqueamento, contribuíram também para a sindicalização do País, ajudando a organizar e liderar

5 Sobre as condições políticas na República, ver Joseph L. Love, "Political Participation in Brazil, 1881-1969", Luso-Brazilian Review, 3, n. 2 (1970): 7-15; Joseph L. Love, São Paulo in the Brazilian Federation, $1889-1937$ (Stanford, 1980); José Murilo de Carvalho, Os bestializados: Rio de Janeiro e a República que não foi (São Paulo, 1987); June Hahner, Poverty and Politics: The Urban Poor in Brazil, 1870-1920 (Albuquerque, 1986).

6 Entre 1890 e 1930 o Brasil recebeu o maior volume de volume de imigrantes, 3,5 milhões, de sua história. A população nacional era de 14,3 milhões em 1890, e 30,6 milhões em 1920. Thomas W. Merrick e Douglas H. Graham, Population and Economic Development in Brazil (Baltimore, 1979), 91. Sobre a ideologia racial brasileira deste período, e a 'tese do branqueamento', ver Thomas E. Skidmore, Black into White: Race and Nationality in Brazilian Thought (Nova York, 1974).

7 Andrews, Blacks and Whites, 54-89; Sam Adamo, "The Broken Promise: Race, Health, and Justice in Rio de Janeiro, 1890-1940" (Tese de Doutorado, Universidade do Novo México, 1983). 
as numerosas greves rurais e urbanas que atingiram seu auge entre 1917 e $1920 .^{8}$

A campanha de europeização combinou-se com a corrupção, a opressão e a estagnação política da República para produzir um crescente descontentamento e oposição ao Estado ruralista. Esporádicos motins urbanos, rebeliões rurais e greves, desde o fim dos anos de 1890 até 1920, deixaram claro o nível de insatisfação popular. Durante a década de 1920 o descontentamento espalhou-se na classe média e nas forças armadas. Três mal sucedidas rebeliões militares aconteceram entre 1922 e 1927, todas lideradas por jovens oficiais, os tenentes. Na sequência das eleições de 1930, em que saiu vencedor, como de costume, o Partido Republicano, os tenentes levantaram-se mais uma vez, agora apoiados pelas elites agrárias, com exceção do setor cafeeiro, que se sentiam excluídas do poder pelos fazendeiros do Sul. Esta quarta rebelião derrubou a República e a substituiu por um governo provisório encabeçado pelo candidato recém-derrotado, Getúlio Vargas. ${ }^{9}$

A "Revolução de 1930" inaugurou um período de intensa atividade política e intelectual no Brasil. Na esfera política, a queda da República abriu possibilidades de expansão da disputa e da participação eleitoral. O Partido Comunista emergiu da clandestinidade para participar abertamente das eleições, assim como o partido fascista recentemente criado: o Integralista. A Constituição de 1934, embora continuasse a barrar o voto dos analfabetos, estendeu o sufrágio às mulheres (apenas o segundo país na América Latina a fazê-lo) e tornou o voto obrigatório. Revertendo completamente a postura contrária a organizações de trabalhadores, o Ministério do Trabalho, criado em 1930, promulgou uma legislação trabalhista e um sistema sindical regulamentado pelo Estado, que desempenhariam importante papel na política brasileira nas décadas

8 Boris Fausto, Trabalho urbano e conflito social, 1890-1920 (São Paulo, 1977); Sheldon Leslie Maram, Anarquistas, imigrantes e o movimento operário brasileiro (Rio de Janeiro, 1979).

9 Boris Fausto, A revolução de 1930 (São Paulo, 1970); Silvio R. Duncan Baretta e John Markoff, "The Limits of the Brazilian Revolution of 1930", Review, 9, n. 3 (1986): 413-52. 
seguintes; seguridade social, saúde pública e outros programas de previdência social também datam destes anos. ${ }^{10}$

Intelectualmente, a década de 1930 assistiu a uma notável explosão de criatividade, quando pensadores brasileiros avaliaram os insucessos da República e, especialmente, sua malfadada campanha de europeização da Nação. Na tentativa de projetar o curso do futuro desenvolvimento do Brasil, seus intelectuais viraram as costas à Europa e voltaram suas atenções ao próprio País, procurando em seu passado as bases históricas sobre as quais construir uma nova e genuína identidade nacional. Como era de se esperar, o que eles viram no passado foi uma história de monocultura de exportação e escravidão africana - base nada promissora para a construção de uma sociedade moderna do século XX. ${ }^{11}$ Pensadores como Francisco José Oliveira Vianna, Afonso Arinos de Mello Franco e Azevedo Amaral rejeitaram a possibilidade de governar esta sociedade segundo normas democráticas e defenderam, ao invés disso, um regime autoritário, governado pelas elites educadas que guiariam o Brasil em direção à modernidade. $^{12}$

Uma reação mais otimista, no entanto, veio do jovem sociólogo Gilberto Freyre. Começando nos anos 1930 e prosseguindo até sua morte em 1987, Freyre desenvolveu o conceito de "democracia racial", um "novo mundo nos trópicos" que tinha conseguido escapar da maldição do racismo europeu e criar uma nova sociedade "além-raça", em que pessoas de todas as cores viviam juntas em relativa paz e harmonia. Isto acontecera, argumentava Freyre, precisamente por causa da intensa e extensa experiência do

10 Sobre este período, ver Robert M. Levine, The Vargas Regime: The Critical Years, 1934-1938 (Nova York, 1970).

11 Brasil recebeu mais escravos africanos que qualquer outro país do Novo Mundo, e aproximadamente dez vezes mais que os Estados Unidos; e manteve a escravidão por mais tempo do que qualquer outra nação ocidental, até 1888. Sobre a importância da agricultura de plantation na história do Brasil, ver Gilberto Freyre, The Masters and the Slaves: A Study in the Development of Brazilian Civilization (Nova York, 1946); James Lang, Portuguese Brazil: The King's Plantation (Nova York, 1979); e Stuart B. Schwartz, Sugar Plantations in the Formation of Brazilian Society: Bahia, 1550-1835 (Cambridge e Nova York, 1985).

12 Ver, por exemplo, Francisco José de Oliveira Vianna, O idealismo da constituição (Rio de Janeiro, 1927); Afonso Arinos de Mello Franco, Introdução à realidade brasileira (Rio de Janeiro, 1933); Azevedo Amaral, O estado autoritário e a realidade nacional (Rio de Janeiro, 1938). 
Brasil com a escravidão africana. Diferente de muitos comentadores do século XIX, em quem ele se fundamentou, Freyre decididamente reconheceu a violência e a brutalidade inerentes à escravidão. Mas sustentou que, apesar de sua feição negativa, a escravidão havia proporcionado um cenário em que europeus e africanos viveram juntos e próximos e no qual, ao longo do tempo, novas formas culturais e sociais foram criadas e profundamente influenciadas pela "herança africana" dos escravos. ${ }^{13}$

A escravidão também criou um cenário propício à miscigenação racial entre senhores brancos e escravas pretas, que, por sua vez, deu origem a um grupo racial completamente novo, os mulatos, estes vistos por Freyre como a mais tangível e conclusiva expressão da democracia racial. Freyre chamou atenção para o fato de que no século XIX os mulatos desfrutaram de evidentes oportunidades de ascensão social nas ocupações especializadas e profissões liberais, e que alguns chegaram a se tornar figuras de proeminência nacional na política e nas artes. A existência deste grupo racialmente mestiço, e a habilidade de seus membros em chegar aos mais altos níveis da sociedade brasileira, constituem prova irrefutável, segundo Freyre, de ausência de preconceito e hostilidade racial, bem como da "democracia racial" no Brasil. ${ }^{14}$

Freyre argumentou, ainda, que o passado escravista do Brasil guardou com ele não só as sementes da harmonia e da igualdade racial, mas também da democracia política e social. O próprio rótulo - democracia racial - reforça seus argumentos, assim como sua ênfase no aspecto "contagiosamente democrático ou democratizante, e até anarquizante, no amalgamento de raças e culturas," e em como este amalgamamento desestabilizava os aspectos "renitentemente aristocráticos" e "patriarcais" da vida brasileira, recolocando "sujeitos" como "cidadãos". ${ }^{15}$ Mesmo durante o escravismo e sob a oligárquica Primeira República, acreditava ele, o Brasil já havia

13 Ver de Freyre, Masters and Slaves; The Mansions and the Shanties: The Making of Modern Brazil (Nova York, 1963); Order and Progress: Brazil from Monarchy to Republic (Nova York, 1970); New World in the Tropics (Nova York, 1959).

14 Freyre, Mansions and Shanties, 354-99; ver também Herbert Klein, "The Colored Freedman in Brazilian Slave Society", Journal of Social History, 3, n. I (1969): 30-52.

15 Freyre, Mansions and Shanties, 231-2; Masters and Slaves, xiv-xv. 
alcançado uma forma de "democracia social", que para ele significava a inclusão de todos os brasileiros em uma sociedade racialmente igualitária; e no momento em que a República fracassou , aquela "democracia social" proporcionava a base sobre a qual se construiria uma democracia política de direito pleno.

O conceito de democracia racial mostrou-se, possivelmente, o produto mais duradouro e influente da agitação intelectual dos anos 30. Com sua reabilitação do passado e prognóstico otimista do futuro do Brasil, ele era muito atraente a todos os brasileiros - negros e brancos, elite e não elite - e ao longo do tempo, desde sua formulação inicial, tem sido elevado a mitologia nacional semioficial. Isto também atraiu considerável atenção internacional, particularmente nos anos que se seguiram a Segunda Grande Guerra, quando o modelo brasileiro de relações raciais foi apontado como o antídoto contra os males do Nazismo europeu e do racismo dos Estados Unidos. ${ }^{16}$

Esta atenção internacional levou a recém-fundada UNESCO a patrocinar uma série de pesquisas, entre o fim dos anos 40 e início dos 50, que procuraram documentar como a democracia racial brasileira funcionava na prática e se poderia ser replicada em outros países. No entanto, em vez de encontrar harmonia e igualdade raciais, muitos dos grupos de pesquisa da UNESCO, especialmente aqueles que trabalharam nas regiões mais urbanas e industrializadas, no Sul e Sudeste, revelaram evidências de desigualdade, preconceito e discriminação raciais bastante disseminados. ${ }^{17}$ Pesquisas seguintes realizadas por estudiosos brasileiros e estrangeiros, nas décadas de 1970 e 1980, têm confirmado esses achados iniciais e têm levado a uma produção de críticas tanto à questionável relação entre a

16 Ver, por exemplo, Frank Tannenbaum, Slave and Citizen: The Negro in the Americas (Nova York, 1946); David J. Hellwig, ed., African-American Reflections on Brazil's Racial Paradise (Philadelphia, 1992).

17 Luis Aguiar Costa Pinto, O negro no Rio de Janeiro (Rio de Janeiro, 1953); Roger Bastide e Florestan Fernandes, Relações raciais entre negros e brancos em São Paulo (São Paulo, 1955); Fernando Henrique Cardoso e Octávio Ianni, Cor e mobilidade social em Florianópolis (São Paulo, 1960). Para representações mais positivas das relações raciais brasileiras, com foco no Nordeste, ver Donald Pierson, Negroes in Brazil: A Study of Race Contact in Bahia (Chicago, 1942); Charles W. Wagley, ed., Race and Class in Rural Brazil (Paris, 1952); Thales de Azevedo, As elites de cor: um estudo de ascensão social (São Paulo, 1955). 
"democracia racial" e a realidade, quanto ao seu papel de baluarte e de defesa da hierarquia e da desigualdade raciais. ${ }^{18}$

Paradoxalmente, embora a democracia racial proclame o Brasil como uma terra de harmonia e igualdade raciais, de fato, a ideologia é baseada numa assunção implícita de inferioridade dos negros. Ela cita a mestiçagem racial, e as amplas oportunidades oferecidas aos frutos da mistura de raças, os mulatos, como a principal evidência de igualdade racial no Brasil. Mas, aos mulatos é concedido este privilégio exatamente porque a ancestralidade racial europeia é vista como superior à africana; as barreiras raciais para ascensão social seriam reduzidas somente à medida que os afrobrasileiros se tornassem menos africanos e mais europeus.

Uma das surpreendentes descobertas da pesquisa dos anos 70 e 80 é que a ideologia da democracia racial exagera em muito as oportunidades realmente abertas aos mulatos. Tomado na sua totalidade, o grupo racial mulato tem alcançado níveis de educação, renda, expectativa de vida etc. que são apenas ligeiramente superiores àqueles atingidos pelos brasileiros de pura ancestralidade africana, embora os dois grupos fiquem bem atrás da população branca. ${ }^{20}$ Contudo, há um número suficiente de mulatos que ascenderam para fornecer abundante evidência fortuita em apoio às afirmações de democracia racial que giram em torno do progresso do mulato. Ao criar essa expectativa de progresso para os mulatos, e ao categorizálos como uma casta separada dos pretos, a democracia racial

18 Nelson do Valle Silva, "Black-White Income Differentials: Brazil, 1960" (Tese de Doutorado, Universidade de Michigan, 1978); Carlos Hasenbalg, Discriminação e desigualdades raciais no Brasil (Rio de Janeiro, 1979); Fontaine, Race, Class and Power; Oliveira, Lugar do negro; Peggy Lovell, "Racial Inequality and the Brazilian Labor Market" (Tese de Doutorado, Universidade da Florida, 1989); Andrews, Blacks and Whites; Peggy Lovell, ed., Desigualdade racial no Brasil contemporâneo (Belo Horizonte, 1991).

19 O próprio Freyre confirma este ponto quando, na discussão sobre a frequência de mobilidade social para os brasileiros racialmente mistos, ele observa que "referimo-nos, é evidente, ao mulato mais claro; a situação do mais escuro, quando a seu favor não intervenham motivos especialíssimos, é quase igual à do negro.” Freyre, Mansions and Shanties, 410.

20 Por exemplo, em 1987 as taxas de alfabetização no Brasil foram de $71 \%$ para os pardos e pretos e $87 \%$ para os brancos. $1 \%$ de pretos e pardos de $2 \%$ se formou na universidade, em comparação com $9 \%$ dos brancos. Os anos médios de escolaridade foram de 1,8 para pretos, 1,9 para os pardos e 3,6 para os brancos. O salário médio dos pretos foi $58 \%$ do salário médio dos brancos, e salário médio dos pardos foi de 57 por cento. IBGE, Pesquisa nacional por amostra de domicílios - 1987. Cor da população (Rio de Janeiro, 1987), vol. 1, Tabelas 2, 4-5, 9. Ver também as fontes citadas na nota 17 . 
incentiva-os a se distanciar dos seus compatriotas mais escuros e tentar incorporar-se à sociedade branca. Os afro-brasileiros talentosos e ambiciosos são então encorajados a virar as costas ao grupo racial não branco; e os não brancos que eles deixam para trás são, por sua vez, divididos em grupos de pardos e pretos, os quais, na maioria, não têm demonstrado muita vontade de unir-se e combater a discriminação que, de fato, afeta fortemente ambos os grupos. ${ }^{21}$

A cooptação de potenciais lideranças e a divisão em subgrupos de pretos e pardos têm sido um obstáculo substancial à mobilização política da população afro-brasileira. A democracia racial obstrui ainda mais tais mobilizações mediante a promoção de um consenso nacional de que, uma vez que o Brasil é de fato uma sociedade racialmente igualitária, não existe base legítima para protesto ou reclamação. De fato, tais protestos são vistos como uma ameaça direta à altamente valorizada harmonia racial do Brasil, e são denunciados como "racismo às avessas". Sendo racismo de qualquer tipo considerado como pecado capital numa democracia racial, os ativistas e as organizações negras não medem esforços para evitar esse ônus - o que por sua vez tem restringido sua capacidade de mobilizar e colocar a questão do racismo e da desigualdade racial na agenda pública. ${ }^{22}$

\section{O novo Movimento Negro e o retorno à democracia, 1975-1990}

Considerando o poder ideológico da democracia racial e os múltiplos caminhos através dos quais ele trabalha para enfraquecer os

21 Em relação a estes impactos de "o mulato como válvula de escape", ver Carl Degler, Neither Black nor White: Slavery and Race Relations in Brazil and the United States (Nova York, 1971), 272-81. Começando na década de 1930 e continuando até o presente, os ativistas afrobrasileiros têm procurado convencer pardos e pretos a ver-se como pertencente a uma categoria racial comum; negro; mas estes esforços foram apenas parcialmente bem sucedidos.

22 Bolivar Lamounier, "Raça e classe na política brasileira", Cadernos Brasileiros, n. 47 (1968): 39-50; Hasenbalg, Discriminação, 241--46; Andrews, Blacks and Whites, 182-86, 227-9. 
esforços individuais e coletivos de combate à desigualdade racial, é quase um milagre que os movimentos negros tenham existido no Brasil do pós-1930. Não obstante, eles existiram, na Frente Negra Brasileira dos anos 30; nas organizações culturais e políticas dos 40 e 50; e no Movimento Negro dos anos 70 e 80. Cada um desses movimentos surgiu em períodos de "abertura" democrática: o governo provisório de Getúlio Vargas (1930-1937); a democracia populista da Segunda República (1946-1964); e os anos da abertura entre 1974-1985. A mobilização política negra esteve intimamente ligada aos esforços de promoção da democracia de modo mais geral; e os ativistas negros tenderam a justificar tal mobilização em termos de promoção de maior participação na vida política e econômica nacional da quase maioria dos grupos raciais que tinham sido historicamente excluídos. ${ }^{23}$

Aqueles líderes e ativistas eram originários principalmente da classe média afro-brasileira, que antes de 1950 era pequena, mas que cresceu de maneira drástica nas décadas do pós-guerra. O Censo de 1940 registrou menos de 13 mil afro-brasileiros, de um total de 14,8 milhões de pretos e pardos, empregados como profissionais liberais e em cargos administrativos. ${ }^{24}$ Em 1980 este número havia crescido para 1.8 milhões, de uma população de preta e parda de 53.3 milhões. ${ }^{25}$ Este crescimento das oportunidades de empregos para a classe média afro-brasileira acompanhou o igualmente drástico crescimento da educação. Em 1940 somente 20 mil não brancos tinham concluído o segundo grau. Em 1980, 1 milhão e cem mil afrobrasileiros tinham diploma de nível médio e 172 mil tinham cursado uma faculdade. ${ }^{26}$

23 George Reid Andrews, "Protesto político negro em São Paulo, 1888-1988", Estudos Afro-Asiáticos, n. 21 (1992): 27-48.

$24 \mathrm{Um}$ adicional de 58.600 afro-brasileiros foi empregado no governo municipal, estadual e federal, mas esta categoria não distingue entre os trabalhadores profissionais e administrativos e os trabalhadores manuais. IBGE, Recenseamento geral do Brasil - 1940. Censo demográfico (Rio de Janeiro, 1950), Tabela 30, pp. 36-7.

25 Dados fornecidos ao autor pelo IBGE. Os valores comparáveis para os brancos em 1980 foram seis milhões de trabalhadores profissionais, técnicos e administrativos, de uma população branca total de 64,5 milhões.

26 IBGE, Recenseamento, 1940, Tabela 25, p. 30; IBGE, Recenseamento, 1980, Tabela 1.5 , pp. 12-13. Entre a população branca, em 1980, 4,4 milhões tinha completado o ensino médio e 729 mil o ensino superior. 
Muitos desses avanços ocorreram durante o milagre econômico, entre 1968-1974, quando o crescimento da economia alcançou taxa média de $10 \%$ ao ano e o governo militar ampliou bastante o sistema de educação superior. Isso resultou num crescimento de níveis de educação e oportunidades de emprego para brasileiros de todas as raças que estavam se esforçando para entrar na classe média. Mas, apesar do inegável progresso que experimentaram nesses anos, os afro-brasileiros que ascenderam socialmente encontraram diante de si barreiras raciais, silenciosas e informais, mas extremamente eficazes, que parece terem sido mais difíceis de superar à medida que eles alcançavam posições mais altas no ranking escolar e profissional. Uma série de estudos sobre os dados do governo relativos à desigualdade salarial nos anos 1960, 1976 e 1980 demonstra isso; mesmo se considerados por idade, experiência, educação, ocupação e outros fatores, diferenças significativas de renda persistiram entre euro-brasileiros e afro-brasileiros. As diferenças eram relativamente pequenas nas profissões menos qualificadas, mas cresciam pronunciadamente nos níveis mais altos do mercado de trabalho. ${ }^{27}$ As pesquisas também mostraram que a proporção dos diferenciais de renda inexplicáveis por educação, experiência etc., quase dobraram entre 1960 e 1980, indicando um crescimento substancial da discriminação durante aqueles anos. ${ }^{28}$

Mesmo antes de o resultado dessas pesquisas estarem disponíveis e amplamente divulgados, um crescente número de afrobrasileiros estavam se tornando cada dia mais exasperados com as barreiras raciais que os afastavam de uma partilha justa dos benefícios do crescimento econômico. Em meados dos anos 70 estes afrobrasileiros, muitos deles jovens e relativamente educados, começaram a debater e discutir entre si os dilemas de viver numa sociedade que não era nem uma democracia política nem, como logo concluíram, uma democracia racial. Esses debates inicialmente aconteciam nas

27 Silva, "Black-White Income Differentials"; Nelson do Valle Silva, "Updating the Cost of Not Being White in Brazil", em Fontaine, Race, Class and Power; Oliveira, Lugar do negro, 47-53; Jeffrey W. Dwyer e Peggy A. Lovell, "The Cost of Being Nonwhite in Brazil", Sociology and Social Research, n. 72 (1988): 136--42; Lovell, "Racial Inequality", 136-39.

28 Silva, "Updating the Cost;" Peggy A. Lovell, "Development and Racial Inequality: Wage Discrimination in Urban Labor Markets, 1960-1980" (artigo inédito apresentado na Conferência Peopling of the Americas, Veracruz, México, 1992). 
recém-fundadas organizações, que, como seus congêneres dos anos 1950, tendiam principalmente a orientar-se para a cultura e a educação. ${ }^{29}$ Muitos dos participantes dessas organizações cedo concluíram que uma abordagem puramente cultural não provocaria impactos imediatos nos padrões de discriminação e desigualdade. E em 1978 um número desses ativistas se reuniu para criar uma nova organização explicitamente política, o Movimento Negro Unificado (MNU).

A decisão de tentar mobilizar a população afro-brasileira para a política foi motivada por eventos no Brasil e no exterior. Afrobrasileiros educados estavam curiosos com e se inspiraram no que viam como uma onda do movimento negro internacional pelo mundo: em particular, a luta pela independência na África portuguesa e os movimentos por direitos civis e o Black Power dos Estados Unidos. Nestes dois exemplos, os negros enfrentaram adversários que aos afro-brasileiros pareceram bastante similares aos que eles mesmos enfrentavam no Brasil: no caso da África, o legado do colonialismo português reforçado pelo autoritarismo de uma ditadura de direita; e no dos Estados Unidos, uma ordem social que tinha abolido a escravidão, mas havia deixado a hierarquia racial intacta. Enquanto ambos os movimentos pareciam alcançar poder e influência, nos anos 70, com a independência das colônias portuguesas e com o decreto e implementação da legislação de oportunidades iguais e ações afirmativas nos Estados Unidos, jovens afro-brasileiros começaram a pensar na possibilidade de repetir essas conquistas no Brasil. ${ }^{30}$

Também no Brasil, a segunda metade da década de 70 parecia oferecer as condições para uma mobilização política em torno das questões raciais. Os militares tinham tomado o poder em 1964 para expurgar da Segunda República os "excessos populistas" e a

29 Exemplos incluem, em São Paulo, o Centro de Cultura e Arte Negra (fundado em 1974) e a Casa de Arte e Cultura Afro-Brasileira (1977), e no Rio de Janeiro, o Instituto de Pesquisa das Culturas Negras (1976). Para uma lista de 573 organizações afro-brasileiras 1988, a maioria deles de orientação "cultural", ver Caetana Damasceno et al., Catalogo de entidades de movimento negro no Brasil (Rio de Janeiro, 1988).

30 Joel Rufino dos Santos, "O movimento negro e a crise brasileira", Política $e$ Administração, 2, n. 2 (1985): 287-307; ver os relatórios periódicos sobre os movimentos negros nos EUA e na África na revista mensal Versus, para o que contribuiu um número de jovens jornalistas negros. Sobre as divergências entre os "africanistas" e "americanistas" no movimento negro, ver Hanchard, "Orpheus and Power", 136-40. 
corrupção, e restaurar o bom funcionamento da democracia. Em 1974, eles julgaram que o processo de purificação estava suficientemente avançado para permitir uma segunda fase de governo militar, um período de relaxamento, distensão e abertura política, que levaria a uma gradual transição para a democracia civil. As eleições para o Congresso em 1974 foram relativamente livres; a reforma partidária de 1979 permitiu a organização de múltiplos partidos de oposição, e eleições para governadores foram realizadas em 1982. O governo militar acabou formalmente em 1985 com a posse de José Sarney, o primeiro presidente civil em 21 anos.

Os militares pretendiam que a abertura fosse um processo em que o governo tivesse total controle do sistema político, enquanto planejavam uma transição cuidadosa e ordeira de volta à democracia "higienizada". A realidade mostrou-se bem diferente. A começar com a retumbante derrota do partido do governo nas eleições para o Congresso, em 1974, e culminando com a desintegração desse partido nas eleições presidenciais de 1985, a oposição civil mostrou-se inesperadamente capaz de reconhecer e explorar as oportunidades de disputar poder com o governo militar. A ala progressista da Igreja Católica organizara os pobres e trabalhadores nas Comunidades Eclesiais de Base que, trabalhando em conjunto com organizações de bairro e comunitárias, fariam pressão sobre os governos locais e nacional por melhorias de serviços, infraestrutura e escolas. Um novo movimento sindical apareceu no cinturão industrial do estado de São Paulo, desencadeando uma onda de greves que se espalhou pelo Centro Sul do Brasil em 1978. Em 79, esse movimento foi a base para a criação do Partido dos Trabalhadores, que dez anos depois chegou perto da Presidência do Brasil. No âmbito da classe média, a imprensa e a Ordem dos Advogados do Brasil brasileiros tornaram-se muito mais ativos no protesto contra a violação de direitos humanos e outros abusos do governo militar, e em empurrar o processo de democratização para frente. ${ }^{31}$

Assim, na segunda metade dos anos 70 , havia um número de fatores a animar a mobilização política negra: um crescente

31 Skidmore, Politics of Military Rule; Alves, State and Opposition; Stepan, Democratizing Brazil. 
sentimento de frustração na classe média negra com as barreiras que continuavam a impedir sua mobilidade social; exemplos concretos de movimentos negros bem sucedidos no exterior; e a mobilização e organização no Brasil, em geral, como resultado da abertura. Tirando proveito da energia gerada pelas celebrações de 90 anos da Abolição - em maio de 1978 - os militantes da classe média perceberam o momento e se articularam para criar o Movimento Negro Unificado. Nascido em São Paulo, o Movimento se espalhou rapidamente por todo o Brasil, com seções sendo abertas no Rio de Janeiro, em Minas Gerais, na Bahia e nos estados do Sul. ${ }^{32}$

Seus membros vislumbravam o MNU, não como um partido político formal, mas como movimento popular que pudesse influenciar e fazer pressão sobre os governos, os partidos e outras importantes organizações com interesse na vida brasileira sindicatos, universidades, o Judiciário, a Igreja - para que combatessem o racismo em suas próprias organizações, e na sociedade em geral, e que dotassem políticas capazes de ampliar as oportunidades econômicas, educacionais, de saúde e outras para toda a população negra. As condições e os termos da abertura tornaram os partidos, em particular, bastante vulneráveis a este tipo de influência. De 1965 a 1979 o governo militar havia permitido somente a dois partidos atuar no Brasil: o partido do governo, a ARENA, e o de oposição, o Movimento Democrático Brasileiro. Num esforço para dividir e enfraquecer seus oponentes, em 1979 o governo abandonou os sistema bipartidário e liberou a oposição para que se organizasse em múltiplas organizações concorrentes. Enquanto a ARENA (renomeada Partido Democrático Social) permaneceu intacta, a oposição dividiu-se em cinco partidos, competindo uns com os outros por apoio eleitoral. Percebendo uma potencial fonte de apoio no novo movimento negro, todos os partidos de oposição apressaram-se em mostrar seu compromisso de combate à discriminação e à desigualdade raciais no Brasil. Inseriram programas antirracistas em suas plataformas políticas, e alguns deles criaram comissões especiais

32 A fundação do MNU é discutida em Lélia Gonzalez, "The Unified Black Movement: A New Stage in Black Political Mobilization", em Fontaine, Race, Class and Power. Ver também Hanchard, "Orpheus and Power", 206-21. 
ou grupos de trabalho para examinar a situação das relações de raça no Brasil e formular propostas políticas adequadas. Os partidos convidaram ativistas negros a se juntar a suas fileiras e indicaram um número sem precedentes de candidatos afro-brasileiros para os cargos eletivos municipais, estaduais e federais em $1982 .{ }^{33}$

Com a atenção dos partidos, no entanto, os ativistas negros tiveram que cumprir a segunda condição para uma organização bem sucedida: responder ao apoio com votos nos partidos de oposição. As eleições de 1982 viram a retumbante vitória dos partidos de oposição nos estados do Sul e Sudeste, onde o movimento negro era mais forte. Mas, somente no Rio de Janeiro, onde o populista Leonel Brizola chegou ao governo do estado com a plataforma do "socialismo moreno", o movimento negro foi decisivo. ${ }^{34}$ Se houve algo de destaque no resultado das eleições, foi o pobre desempenho de candidatos estreitamente ligados ao movimento negro. Por exemplo, de 54 candidatos afro-brasileiros que concorreram em São Paulo pelos principais partidos, somente dois - um deputado estadual e um vereador da capital - venceram as eleições. ${ }^{35}$

Como observou um ativista negro na sequência das eleições, "muita gente blefou; disse que tinha tantos votos e, na hora da apuração, viu que não tinha nada". ${ }^{36}$ Dados de pesquisa realizada em São Paulo mostraram que, entre os eleitores afro-brasileiros menos de um quarto havia votado em candidatos negros. No entanto, esta proporção variou substancialmente por classe. Na classe média alta, 43\% tinham votado em candidatos negros; entre as ocupações técnicas e administrativas, $27 \%$ votaram em candidatos negros; entre os trabalhadores manuais (que compunham a maior parte dos votantes e a esmagadora maioria do eleitorado negro), somente $19 \%$ votaram em candidatos negros. ${ }^{37}$

33 A disputa dos partidos pelo voto negro é descrita em João Baptista Borges Pereira, "Aspectos do comportamento político do negro em São Paulo", Ciência e Cultura, 34, n. 10 (1982): 1286-94; Ana Lucia E.F. Valente, Política e relações raciais: os negros e as eleições paulistas de 1982 (São Paulo, 1986).

34 Glaucio Ary Dillon Soares e Nelson do Valle Silva, "Urbanization, Race, and Class in Brazilian Politics", Latin American Research Review, 22, n. 2 (1987): 155-76.

35 Valente, Política e relações raciais, 73-78.

36 "Movimento negro avalia sua importância", Folha de São Paulo (15 de abril de 1984).

37 Valente, Política e relações raciais, 139. 
Candidatos associados ao movimento negro tinham apelo mais forte entre os negros relativamente mais bem educados e socialmente melhor posicionados do que entre os eleitores da classe trabalhadora. Isso era, em parte, um reflexo das origens sociais e preocupações de muitos ativistas e candidatos negros, que tendiam a distanciá-los da massa de votantes afro-brasileiros. ${ }^{38}$ Essa distância, por sua vez, refletia o problema maior da profunda desigualdade que caracteriza a sociedade brasileira e os obstáculos que essa desigualdade coloca a quaisquer mobilizações populares. O Brasil tem uma longa história, que remonta à escravidão, de extrema concentração de riqueza e poder em mãos de uma elite relativamente pequena. ${ }^{39}$ A exclusão de brasileiros pobres teve como consequência que "em regra, os setores populares são um tanto céticos em relação a possibilidades de mudanças políticas efetivas. A política é vista como uma briga da elite, e o Estado é percebido como um reino além dos setores populares". Dada à experiência histórica do Brasil, tais atitudes não são de todo inoportunas ou irrealistas; "embora limitem as possibilidades de uma ação coletiva, somente quando as pessoas acreditarem na eficácia de ações coletivas é possível organizar um movimento social". 40

Este ceticismo claramente atinge o problema do racismo e da desigualdade racial. Pesquisas indicam que independentemente da classe social, muitos afro-brasileiros têm experimentado discriminação racial ou são conscientes da sua existência. Embora, nas discussões sobre possíveis respostas a tais discriminações, somente um punhado de informantes levantem a possibilidade de uma ação política organizada. As respostas mais frequentes são que não

38 Sobre as reclamações da classe trabalhadora relativas à retórica "elitista" de muitos dos ativistas negros, ver: "Movimento negro já conta 400 entidades e cresce no Brasil", Jornal do Brasil (12 de maio de 1985); Celma Rosa Vieira, "Negra: mulher e doméstica", Estudos AfroAsiáticos, 14 (1987), 154-56; "Em pauta: o movimento negro", Maioria Falante (novembrodezembro de 1988): 8-9.

39 Charles H. Wood e José Alberto Magno de Carvalho, The Demography of Inequality in Brazil (Cambridge e Nova York, 1988).

40 Scott Mainwaring, "Grassroots Popular Movements and the Struggle for Democracy", in Stepan, Democratizing Brazil, 183. Ver também Teresa Caldeira, A política dos outros: o cotidiano dos moradores da periferia e o que pensam do poder e dos poderosos (São Paulo, 1984); Nancy Scheper-Hughes, Death Without Weeping: The Violence of Everyday Life in Brazil (Berkeley, 1992), 505-16. 
existe solução para o problema, ou que o informante não tem ideia de que solução poderia haver. ${ }^{41}$

Tais sentimentos de impotência e incerteza refletem em parte a qualidade difusa e sistêmica da desigualdade racial, que é tão profundamente enraizada na vida brasileira, que não há como saber como ela pode ser mais efetivamente combatida e erradicada. Mas a desigualdade racial também faz parte de um padrão mais amplo de desigualdade que, como indicado acima, tem excluído e marginalizado movimentos populares da participação na política nacional e nos assuntos de Estado. Nesse tipo de ambiente, os brasileiros pobres e os que não são da elite têm concluído que a forma mais efetiva de lidar com os problemas causados pela pobreza e falta de poder não é organizar-se coletivamente e pressionar por mudanças políticas. Ao contrário, é estabelecer laços pessoais diretos com protetores poderosos que possam amparar e fazer favores a sua clientela. $^{42}$

Como outros movimentos populares que apareceram durante o período da abertura, o movimento negro propunha um repúdio a este modelo de relações sociais e políticas baseadas no clientelismo e substituí-la por uma "nova ordem social" baseada na mobilização de massa e na ação coletiva. Não surpreende que muitos eleitores negros, e especialmente muitos negros pobres e da classe trabalhadora, relutassem em apostar numa aventura tão arriscada. ${ }^{43} \mathrm{~A}$ primeira vítima dessa relutância foi o próprio MNU, que nunca se recuperou

41 Valente, Política e relações raciais, 125-8; Jorge Aparecido Monteiro, "Cor e trabalho na empresa pública: Uma introdução", Série Estudos JUPERJ, n. 56 (1987): 45, 75.

42 Ver a caracterização de Roberto da Matta da vida brasileira como "um universo relacional", no qual "pode-se negar tudo menos o pedido de um amigo"; ou a observação de Roberto Schwarz que, no Brasil, "o favor é a nossa mediação quase universal". Roberto da Matta, A casa e a rua: espaço, cidadania, mulher e morte no Brasil (São Paulo, 1985), 55-80 passim; Roberto Schwarz, Ao vencedor as batatas (São Paulo, 1977), 16. Sobre as raízes históricas desse modelo, ver Richard Graham, Patronage and Politics in Nineteenth-Century Brazil (Stanford, 1990); Costa, Brazilian Empire, 188-96, 241-44.

43 A antropóloga Nancy Scheper-Hughes relata que seus informantes em uma pequena cidade do Nordeste, que são pobres e a maioria afro-brasileiros, "os eleitores votam nos candidatos municipais, estaduais e nacionais que têm mais probabilidade de ganhar e vão evitar associação com prováveis perdedores, mesmo que o candidato 'mais fraco' expresse solidariedade com a sua classe. Como Tonieta [uma das mulheres da comunidade] qualificou seu apoio aos lideres políticos locais, 'Se você está subindo, eu vou seguir junto com você. Se você está caindo, adeus, pode ir sem mim". Scheper-Hughes, Death Without Weeping, 473. 
completamente do desastroso desempenho de 1982. Embora continue a existir como organização nacional com seções em todo o Brasil, um de seus fundadores lembra que "foi se reduzindo ideologicamente ... Depois de um ano, perdeu militantes e força."

Embora ativistas se afastassem do MNU, eles não abandonaram a luta contra a desigualdade racial. Alguns continuaram empenhados em organizar negros pobres e trabalhadores negros, mas agora sob a égide de instituições convencionais, como a ala progressista da Igreja Católica ou os partidos políticos de esquerda. ${ }^{45}$ Outros, no entanto, levaram seu trabalho a outro nível e objetivaram diferentes públicos. Em seus anos iniciais o MNU devotou considerável energia a conscientização da população negra, trabalhando para expor as contradições internas da doutrina da democracia racial e as disparidades entre a doutrina e as rigorosas realidades da hierarquia racial brasileira. Apesar ou por causa do fracasso desses esforços para motivar em larga escala, numerosos militantes negros ampliaram seus apelos para atingir uma base nova e diferente: a população branca, e especialmente as elites culturais , intelectuais e políticas brancas.

\section{Contestando a democracia racial}

Foi o intelectual e ativista negro Joel Rufino dos Santos quem primeiro articulou como o conceito de democracia racial, que era um obstáculo à mobilização da população negra, poderia ser funcional na persuasão da opinião pública branca. Joel Rufino observou que, ainda que as asserções da democracia racial encontrassem pouco suporte na realidade empírica, elas tinham, no

44 "Movimento negro avalia sua importância."

45 Ver, por exemplo, perfis do ativista / sacerdote Frei David Raimundo dos Santos, ou da deputada Benedita da Silva, favelada eleita em 1986 pelo Partido dos Trabalhadores. Jane Kramer, "Letter from the Elysian Fields", The New Yorker (2 March 1987): 40-74; "One Woman's Mission: To Make Brasilia Sensitive", New York Times (9 de fevereiro de 1987): 4. 
entanto, ensinado os brasileiros a valorizar muito os ideais de igualdade racial e harmonia. Ele distinguiu o mito de igualdade racial, "que é falso", do "desejo ardente da [verdadeira] democracia racial", que acreditava que a maioria dos brasileiros compartilhasse. Se os brasileiros brancos fossem levados a ver a disparidade chocante entre o mito e a realidade, talvez fossem movidos a agir contra a discriminação e o racismo que manchavam os seus ideais nacionais. ${ }^{46}$

Como na reforma partidária de 1979, novamente as condições específicas dos anos da abertura fizeram os políticos e intelectuais brancos particularmente receptivos aos apelos dos ativistas negros. Desde a década de 1930, os ativistas negros tentavam chamar a atenção pública para a dimensão racial da desigualdade brasileira, argumentando que não ser possível dizer que a democracia política ou a democracia racial existissem no Brasil até que pessoas negras participassem da economia, política e vida social nacional em igualdade de condições com os brancos. Esses argumentos começaram a ser levados a sério por um punhado de intelectuais e acadêmicos brancos durante os anos de 1950 e 1960 e, assim, circularam mais amplamente nos trabalhos de uma nova geração de cientistas sociais resultante da expansão do sistema universitário durante a década de 1970. Esses estudiosos assumiram a questão da raça como parte de uma crítica mais ampla da desigualdade na sociedade brasileira e nos modos pelos quais essa desigualdade representava obstáculos fundamentais para a construção de normas e instituições democráticas. Desse modo, eles tornaram cada vez mais clara a conexão entre democracia política e democracia racial, argumentando que, em uma sociedade altamente desigual, racialmente estratificada como o Brasil, uma não pode existir, genuinamente, na ausência da outra. ${ }^{47}$

Enquanto isso, políticos e intelectuais de oposição também tinham chegado a ver o conceito de democracia racial como uma pedra angular de um aparato ideológico maior, através do qual as 1980): 7-11.

46 "Democracia racial, o mito e o desejo", Folhetim. Folha de São Paulo (8 de junho de

47 Este argumento é defendido de forma mais eficaz em Fernandes, Integração do negro; e Octavio Ianni, "Diversidades raciais e questão nacional", in Raças e classes sociais, $2^{\text {a }}$ ed. (São Paulo, 1988). Ver também outros trabalhos citados na nota 17. 
elites conservadoras da nação procuravam manter e justificar o controle sobre a sociedade. Durante o século XIX e a Primeira República, as elites fundiárias tinham repetidamente caracterizado $\mathrm{o}$ sistema político que eles presidiam como uma democracia participativa, quando era, de fato, um regime oligárquico firmemente controlado, o qual, particularmente após a reforma eleitoral de 1881, limitava incisivamente a participação popular. $^{48} \mathrm{O}$ resultado, argumentaram os teóricos do Partido dos Trabalhadores e seu secretário geral, Francisco Weffort, foi um "legado de equívocos" em que o autoritarismo se mascarou de democracia. ${ }^{49}$

Se uma das tarefas centrais na construção da democracia civil foi limpar aquele "legado de equívocos", o mito envelhecido e visivelmente falso da democracia racial, que formava uma parte tão integral daquele legado, parecia um bom lugar para começar. A democracia racial se fez ainda mais vulnerável pelo modo como os governos militares procuraram aproveitar-se dela. Apesar da determinação com que haviam tomado o poder em 1964 e se agarrado a ele nas próximas duas décadas, os militares nunca estiveram inteiramente à vontade com a decisão de acabarem com a democracia. Frequentemente lembravam àqueles que os ouviam que haviam destruído a democracia brasileira justamente para salvá-la, e que o seu objetivo de longo prazo era limpar e reestruturar suas instituições de tal forma que a democracia fosse eventualmente capaz de funcionar no Brasil livre dos "excessos" e da corrupção que a haviam marcado no passado. ${ }^{50}$ Enquanto isso, durante o período em que o Brasil claramente não era uma democracia política, foi útil para a ditadura ser capaz de reivindicar que o País continuava a ser democrático em pelo menos um sentido: o da raça. Os governantes defenderam este ponto repetidamente, e classificaram qualquer crítica à democracia

48 Sobre a reforma eleitoral, que reduziu o sufrágio de aproximadamente um milhão de eleitores para menos de 150 mil, ver Graham, Patronage and Politics, 182-206.

49 Francisco Weffort, Por que democracia? (São Paulo, 1985), 21-31. Weffort cita o historiador Sérgio Buarque de Holanda, um dos pensadores seminais da década de 1930, que caracterizam a democracia brasileira como "sempre um lamentável mal-entendido. Uma aristocracia rural e semifeudal a importou e tentou acomodá-la, onde fosse possível, aos seus direitos e privilégios."

50 Silvio Duncan Baretta e John Markoff, "Brazil's Abertura: A Transition from What to What?" in James M. Malloy e Mitchell A. Seligson, eds., Authoritarians and Democrats: Regime Transition in Latin America (Pittsburgh, 1987), 53-57. 
racial como um ato de subversão. ${ }^{51}$ Assim, no momento da abertura, o conceito havia sido desacreditado tanto por sua associação com o autoritarismo de direita quanto por sua questionável relação com a realidade. Não só era mais fácil combater empiricamente o conceito; para muitos brasileiros, fazê-lo era um ato de liberação política, e de rejeição explícita da ditadura.

Os anos 1980 foram, assim, um momento propício para os ativistas negros assumirem a ideologia nacional de democracia racial, o que eles fizeram em uma variedade de foros: encontros públicos e palestras, artigos de jornais e editoriais, debates e outros recursos no rádio e na TV, conferências acadêmicas e até em festivais de canções populares e de samba. Essas atividades atingiram um clímax durante as comemorações do centenário da Abolição da escravidão, em maio de $1988 .^{52}$

O conteúdo dessas festividades, especialmente daquelas patrocinadas não pelo movimento negro, mas por instituições tradicionais como a Igreja, as universidades e governos federais, estaduais e municipais, deixa claro em que medida o consenso nacional de democracia racial havia se despedaçado durante os anos de 1980. O Ministro da Cultura Celso Furtado, cujo ministério coordenou a comemoração do evento com patrocínio federal, abriu as festividades proclamando que "é falsa a ideia de que há democracia racial no país, enquanto a maioria esmagadora da população negra vive na marginalidade". ${ }^{3}$

$\mathrm{O}$ candidato do partido dos Trabalhadores à presidência, Luis Inácio Lula da Silva, sem dúvida com um olho nas eleições de 1989, denunciou a democracia racial como "apartheid de fato". ${ }^{54}$ A igreja Católica, que fez das relações raciais o tema central da sua Campanha da Fraternidade de 1988, emitiu um texto instrucional reconhecendo a cumplicidade da igreja, no passado, com a escravidão e a

51 Azevedo, Democracia racial, 53; ver também Gilberto Freyre, “A propósito de preconceito de raça no Brasil", O Estado de São Paulo (25 de junho de 1969).

52 Para os eventos do centenário, ver Yvonne Maggie, ed., Catálogo: Centenário da abolição (Rio de Janeiro, 1989).

53 "Vem ai cem anos de ebulição", A Gazeta (13 de maio de 1988): 13; "Prêmio Nobel cobra mais ação contra apartheid", Folha de São Paulo (13 de maio de 1988): 11.

54 Luis Inácio "Lula" da Silva, "A mistificação da democracia racial", Folha de São Paulo (16 de fevereiro de 1988): 3. 
discriminação racial e pedindo esforços sistemáticos para eliminar a injustiça racial no Brasil. ${ }^{55}$

$\mathrm{Na}$ imprensa, os dois maiores semanários de notícias se uniram para mandar a democracia racial à lata de lixo da história. "Parece estar definitivamente enterrado ... o mito da democracia racial", observou a IstoÉ, enquanto a Veja implicitamente descartou o conceito abrindo a sua matéria de capa com a observação: "passados 100 anos da Abolição, há no Brasil duas cidadanias distintas - a branca e a negra". ${ }^{56}$ A Folha de São Paulo publicou um editorial sobre "a percepção, cada vez mais difundida, de que a 'democracia racial', como propalada pelas versões oficiais e oficialescas, não coincide com a realidade do país." No Rio, o Jornal do Brasil entrevistou intelectuais e figuras públicas que eram praticamente unânimes em seu repúdio ao conceito. O historiador Francisco Iglesias secamente o descartou como "tolice", enquanto o seu colega Décio Freitas virou o conceito de cabeça para baixo insistindo que "a discriminação racial é a base da cultura brasileira". O Sociólogo Octávio Ianni captou o clima do momento observando que "mais do que ninguém, o negro sabe que a democracia racial é uma mentira em um país em que não há democracia política e muito menos democracia racial". ${ }^{57}$

Nem toda a retórica em torno do centenário teve caráter tão revisionista. Mas o tom geral de crítica e hostilidade à ideologia da democracia racial marcou um rompimento radical com as tradicionais garantias tranquilizadoras da harmonia e igualdade racial do Brasil. As propostas políticas apresentadas, e em alguns casos promulgadas, durante o ano do centenário não foram menos drásticas. Inspiradas nas políticas de ações afirmativas dos Estados Unidos, o ministro da Cultura, Celso Furtado, protestou por garantia de um número mínimo

55 "Ouvi o clamor deste povo"... negro (Petrópolis, 1987).

56 "Cem anos, sem quase nada", lstoÉ (20 de abril de 1988): 30-33; "Na segunda classe", Veja (11 de maio de 1988): 22-30.

57 "Cem anos depois", Folha de São Paulo (13 de maio de 1988): 2; "Cem anos de solidão", Caderno B, Jornal do Brasil (8 de maio de 1988): 8. Para outras denúncias de desigualdade racial, ver os suplementos sobre "Abolição: 100 anos", Diário Popular (12 de maio de 1988); "Vem ai cem anos de ebulição", A Gazeta (13 de maio de 1988): 13-18; "Brasil: os negros, hoje", Manchete (21 de maio de 1988): 4-9; "Another Myth Bites the Dust", The Brasilians (MaioJunho de 1988): 2. 
de vagas em escolas e universidades brasileiras para estudantes afrobrasileiros. O presidente Sarney estabeleceu uma nova agência federal, a Fundação Palmares, encarregada de promover "a presença negra em todos os setores de liderança deste país." E a recentemente promulgada Constituição de 1988 incluiu um item declarando a discriminação racial uma ofensa criminal e negando o direito de fiança aos réus acusados deste crime. ${ }^{58}$

\section{Conclusões}

Essas iniciativas políticas, e a comemoração revisionista do centenário, representa o ponto culminante do movimento político negro no Brasil. Desde 1988, o movimento declinou marcadamente em importância e influência, por razões importantes para o futuro da democracia brasileira.

Primeiro, membros da classe média, negros e brancos, tiveram um papel proeminente nos eventos em discussão. A maior parte da liderança e força motriz do movimento negro veio da recusa aos afro-brasileiros em ascensão de admissão na classe media. E o movimento encontrou parte de sua audiência mais receptiva não entre negros pobres e da classe trabalhadora, mas entre intelectuais e ativistas brancos, que incorporaram a questão da raça na sua crítica geral à desigualdade no Brasil moderno.

Muito do fracasso do movimento em mobilizar a população negra pode ser buscado nas diferenças que separavam os militantes da classe média de sua base pobre e trabalhadora. Mesmo na classe média, entretanto, o movimento negro mostrou-se limitado no seu apelo, por causa do poder de ideologias oficiais e semioficiais de estabelecer as condições em que se dão a participação e a disputa política. Desde a década de 1930 até o presente, a ideologia da democracia racial tem tido um papel central em obstruir a

58 "Abolição é exemplo de congraçamento e união", $O$ Globo (13 de maio de 1988): 6; "Racismo é crime", O Estado de São Paulo (3 de fevereiro de 1988). 
organização política negra e em abafar o debate público sobre a desigualdade racial. Ela continuou a representar este papel nos anos de 1970 e 1980, ajudando a afastar o apoio negro no nível tanto da classe média como da trabalhadora.

Não obstante, o poder de tais ideologias não é absoluto, como fica evidente no fracasso da democracia racial em sobreviver intacta aos anos de 1980. Este fracasso sugere que mesmo as mais potentes e duráveis ideologias nacionais são inerentemente instável; e aquelas que se baseiam em clamores por justiça e igualdade são talvez as mais vulneráveis a serem dilaceradas por suas tensões internas e contradições. Em um ato habilidoso e criativo de desconstrução política, os ativistas negros conseguiram transformar a ideologia que tanto havia impedido seu trabalho de organização em uma ferramenta poderosa para construir alianças com os brancos oponentes do governo militar. Como parte de sua própria campanha para minar a fundamentação ideológica do autoritarismo e superar a herança de longa data de desigualdade social e econômica do Brasil, políticos e intelectuais de oposição juntaram suas vozes ao movimento negro para denunciar a disparidade entre as reivindicações oficiais de democracia racial e a realidade objetiva de desigualdade racial e de discriminação. $O$ resultado foi uma transformação marcante nos termos e conteúdos do discurso político sobre raça no Brasil, e, à medida que partidos de oposição chegaram ao poder, o início da ação do Estado de combate às desigualdades raciais.

Essas mudanças na retórica e política oficiais provocaram alguns impactos imediatos e mensuráveis nas relações de raça no Brasil. No estado de São Paulo, seguindo as celebrações do centenário de 1988 e a adoção de fortes medidas antidiscriminação na Constituição, quase três vezes mais queixas de discriminação racial foram apresentadas à polícia em 1989 e 1990 do que durante os 34 anos anteriores (1954-1988) juntos. ${ }^{59}$ No nível nacional, as eleições de 1990 colocaram três governadores de estado negros no poder, um evento sem precedentes na política brasileira. De forma significativa, entretanto, nenhum dos três era associado ao movimento negro ou

59 "Racismo em São Paulo motiva 64 processos em 2 anos", Folha de São Paulo (27 de janeiro de 1991). 
havia ressaltado questões raciais em sua campanha; e de fato, no final da década, o braço político do movimento negro estava extinto, tendo quase nenhum papel nas eleições presidenciais de 1989 ou nas eleições governamentais e para o Congresso no ano seguinte. ${ }^{60}$ Isto, por sua vez, tornou possível para defensores do status quo desconstruir as medidas propostas ou promulgadas durante as celebrações do centenário. As propostas do ministro da Cultura Celso Furtado para uma política de ações afirmativas na educação brasileira morreram no ninho; o orçamento da Fundação Palmares foi cortado em 1990, como parte do programa de austeridade do presidente Fernando Collor; e quando o Congresso aprovou a legislação que permitia disposições antidiscriminação da nova Constituição, o presidente Sarney vetou a cláusula que negava o direito de fiança a pessoas acusadas de discriminação. ${ }^{61}$

Esses retrocessos sugerem uma conclusão final: as severas limitações de uma estratégia política baseada principalmente em apelos de consciência e valores nacionais. Sugerem, ainda, os perigos de os ativistas negros abraçarem o que em essência foi simplesmente uma nova variação da tradicional política do clientelismo, em que intelectuais articulados, mas sem poder, buscaram suporte, proteção e favores de instituições e elites brancas poderosas. Os ativistas negros estavam seguindo a mesma abordagem consagrada pelo tempo empregada pelos seus compatriotas mais pobres, contando mais com o clientelismo do que com mobilizações e ações coletivas. A recompensa por tais táticas pode ser substancial, como fica evidenciado na reformulação do discurso racial que ocorreu durante a década de 1980 e nos avanços das proteções legais dos direitos civis dos negros. Mas ao desistir dos esforços para mobilizar maior apoio popular, o Movimento Negro perdeu a possibilidade de conquistar o peso político necessário para transformar esses avanços significativos, mas isolados, em uma campanha mais completa e efetiva contra a

60 "Negros no governo", Veja (5 de dezembro de 1990): 40-41; "Em pauta: O movimento negro;" "A esquerda que o negro quer", Maioria Falante (dezembro de 1989-janeiro de 1990): 6-7; "Negros trocam militância por nova identidade", O Estado de São Paulo (12 de novembro de 1991). de 1989).

61 "Sarney sanciona lei que pune os crimes raciais", Folha de São Paulo (6 de janeiro 
desigualdade racial, e para ir do discurso à formulação real de políticas públicas.

A durabilidade desse modelo clientelista de política, mesmo - ou especialmente - nos movimentos políticos progressistas, focados em combater as profundas desigualdades na sociedade e na política brasileiras, sugere a continuidade do poder desse modelo, e das desigualdades das quais ele é uma expressão, para moldar o caráter da democratização no final do século XX no Brasil. Patronagem e clientelismo continuam sendo características basilares da competição política no Brasil; e mesmo a democracia racial, ainda que amplamente repudiada entre elites progressistas, mantém um vigor considerável na sociedade como um todo. É pouco provável que a democratização no Brasil derrube essas estruturas, pelo menos no curto prazo; supõe-se que, pelo menos, as instituições da Terceira República irão imprimir sua própria marca. Com certeza, a desigualdade racial não parece estar em declínio; em alguns indicadores, ela na verdade aumentou levemente no curso da década de $1980 .{ }^{62}$ O sucesso do movimento negro em colocar a questão da desigualdade na agenda pública foi uma conquista histórica; mas a sua inabilidade em provocar uma ação governamental mais sistemática nesta área deixa esta questão sem solução, por enquanto e no futuro próximo.

RECEBIDO EM: 02/01/2016 APROVADO EM: 19/04/2016

62 George Reid Andrews, "Desigualdade racial no Brasil e nos Estados Unidos: uma comparação estatística", Estudos Afro-Asiáticos, n. 22 (1992): 47-83. 